\title{
High-cycle fatigue investigations of notched Glare under different stress ratio's in various environments
}

\author{
Sunil Bhat ${ }^{1^{*}}$ and Sockalingam Narayanan ${ }^{2}$
}

\begin{abstract}
Notched Glare 4A-3/2 laminates, comprising thin 2014-T6 aerospace aluminum alloy sheets alternately bonded with unidirectional E-glass fiber-based composite prepregs, are tested under tensile-tensile fatigue load with different stress ratio's ranging from 0.1 to 0.5 in ambient, aqueous, and corrosive environments in high-cycle conditions. Fatigue characteristics of the laminates are found to be influenced by the operating environment and the magnitude of stress ratio. Notched plain 2014-T6 aerospace aluminum alloy specimens are also subjected to identical cyclic stress levels as in aluminum alloy layers of the laminates for comparative analysis of their fatigue behavior with those of the laminates. Retarded crack growth rates in the laminates leading to their enhanced fatigue lives and higher cyclic fracture toughness values vis-à-vis plain specimens substantiate fiber bridging effect in the laminates.
\end{abstract}

Keywords: Aqueous environment; Corrosive environment; Fatigue life; Glare; Stress ratio

\section{Background}

Glare, a fiber metal laminate (FML), consists of layers of thin and light aerospace aluminum alloy sheets that are alternately bonded and cured with composite prepregs by heat and pressure, each prepreg is built up of several resin-impregnated unidirectional fiber cloth layers laid in similar or different orientations. Besides offering gain in specific strength, Glare exhibits properties like excellent fatigue and fracture resistance, reasonably good impact strength, and high fire resistance that make it a good substitute for monolithic aluminum alloys especially in aerospace applications.

Numerous studies have so far been reported on behavior of various types of FMLs under fatigue loads of constant and variable stress ratios with most of them pertaining to tests conducted in ambient environment only. Notably, in the field of fatigue of FML under load cycles of constant stress ratio in ambient environment, Lin et al. 1991 discussed fatigue behavior in carbon- and aluminum-based FML (Care), followed by Lin and Kao (1995) investigating the effect of fiber bridging and delamination growth (Lin

\footnotetext{
* Correspondence: ss.bht@rediffmail.com

'School of Civil and Mechanical Engineering, Galgotias University, Greater Noida, UP 203201, India

Full list of author information is available at the end of the article
}

and Kao 1996) on crack propagation in the laminate. Guo and Wu (1998, 1999a, 1999b) presented theoretical and phenomenological models for predicting fatigue crack growth characteristics and bridging stress distribution in FML. Homan (2006) observed that fatigue crack initiation in FML depends upon the magnitude of stress in metal layer. He also investigated the effect of residual stress in fibers and in metal layers over the crack tip. Alderliesten and Homan (2006) discussed fatigue and damage tolerance issues of Glare in aircraft structures. Suiker and Fleck (2006) presented the relation between fatigue crack growth rate and remote cyclic stress with and without delaminations in a FML. Takamatsu et al. (1999) examined fatigue crack growth in Glare and checked the validity of proposed analytical models. Alderliesten (2007a) studied the propagation of fatigue cracks in aluminum layers of Glare in the presence of delaminations at aluminum-fiber interfaces. He postulated that the stress intensity parameter at the crack tip is the function of far-field opening stress and closing bridging stress in aluminum layers. An analytical model for fatigue crack propagation and transverse delamination extension using the correlation between growth rate and energy release rate of the delamination was proposed by him. The model was implemented 
in a numerical program, and the results were validated with the range of experimental data. Good agreement between crack growth rates, crack opening contours, and delamination shapes was obtained. Alderliesten (2007b) reviewed phenomenological, analytical, and finite element models for fatigue crack propagation prediction in Glare. Chang and Yang (2008) examined fatigue crack growth in Glare by modulating the stress intensity parameter with a bridging factor and obtained the S-N curve based on the initiation and growth life of the crack. Paris law was employed to predict crack growth rates. Shim et al. (2003) adopted a mechanistic approach to predict fatigue crack growth in Glare with the help of Paris law. Kawai and Kato (2006) examined the effects of stress ratio on off-axis fatigue behavior of Glare. They tested the coupons under different stress ratios of $0.1,0.4$ and -0.2 . A fatigue damage model to account for the effect of stress ratio on crack characteristics was developed. Likewise, in the field of fatigue of FML under load cycles of variable stress ratios in ambient environment, Kawai and Hachinobe (2002) examined the effects of change in amplitude of load during the test on off-axis fatigue strength of Glare. The results of two-stress level cycles were compared with those of constant amplitude cycles. Khan et al. (2010) predicted the fatigue crack growth in Glare when subjected to variable amplitude cycles by using modified Wheeler model based on Irwin's crack tip plasticity correction and validated the theoretical results with the help of experiments.

Limited work is reported on fatigue behavior of FMLs under different stress ratios in other possible operating environments although successful attempts have been made to evaluate their properties and performance in high temperature. For instance, Rans et al. (2011) presented an analytical model to predict fatigue crack growth rate in FML operating in high temperature. The model was validated with experimental data collected in ambient conditions. da Costa et al. (2012) investigated the influence of thermal shock cycles on mechanical properties of FML. FML coupons, under cyclic load, were exposed to fast temperature transition from $-50^{\circ} \mathrm{C}$ to $+80^{\circ} \mathrm{C}$. Tensile and inter-laminar shear strengths of coupons were measured after 1,000 and 2,000 cycles. No significant changes were found in micro-structure and mechanical properties of exposed coupons vis-à-vis the unexposed ones. This paper presents experimental results of series of notched Glare laminates subjected to tensile-tensile fatigue cycles with different stress ratios ranging from 0.1 to 0.5 in aqueous and corrosive environments. The laminates are tested in ambient environment as well. The stress ratio is kept constant during each test while fulfilling high-cycle conditions in the laminates. Notched plain aerospace aluminum alloy specimens are also tested under identical cyclic stress levels as those in aluminum alloy layers of the laminates for comparative analysis between them and the laminates.

\section{Glare details}

Refer to Figure 1. Glare in the present work comprises three thin layers of 2014-T6 aerospace aluminum alloy and two prepregs, each prepreg is built up of three composite layers in the sequence $\mathrm{c} 0-\mathrm{c} 90-\mathrm{c} 0$. A composite layer consists of 4-mil or $0.1-\mathrm{mm}$ thick unidirectional E-glass fiber cloth of grammage 110 gsm coated with CY205 epoxy resin (HY905 as hardener) on both sides. The volume fractions of fiber and resin in a composite layer are 0.522 and 0.478 . Composite $\mathrm{c} 0$ has fibers laid in the $y$ direction, i.e., along the direction of rolling of aluminum alloy, whereas composite $\mathrm{c} 90$ has fibers oriented in the $x$ direction, i.e., transverse to the rolling direction of aluminum alloy. The grade of laminate with chosen configuration is Glare 4A-3/2 (4A denoting 0-90-0 orientation of composites in prepreg, and $3 / 2$ representing number of aluminum alloy layers and prepregs in the
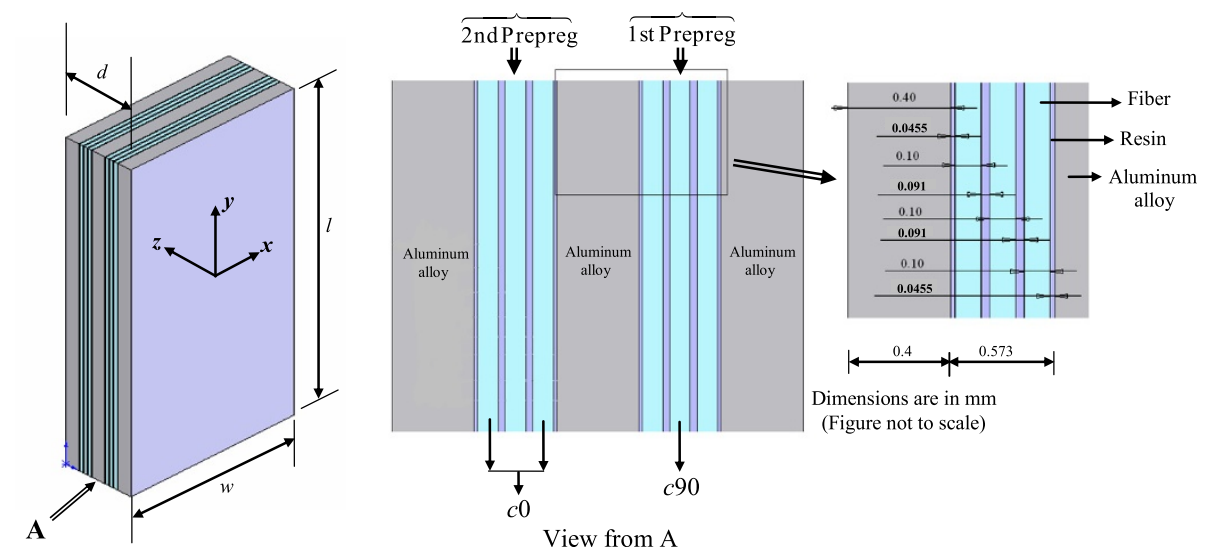

Figure 1 Glare laminate. 
laminate). The properties of the constituent materials (Callister 2004) are displayed in Table 1. The standard/ desired dimensions of the laminate and its ingredients are the following: $l=200 \mathrm{~mm}, w=50 \mathrm{~mm}, d=2.346 \mathrm{~mm}$, $t_{\mathrm{al}}=0.4 \mathrm{~mm}, t_{\mathrm{r}}=0.0455 \mathrm{~mm}, t_{\mathrm{f}}=0.1 \mathrm{~mm}, t_{c 0}=0.191 \mathrm{~mm}$, and $t_{c 90}=0.191 \mathrm{~mm}$.

The laminate is loaded in the $y$ direction because it demonstrates good strength and fatigue properties due to more number of c0 composites in prepregs. Since the material layers in the laminate are elastically unidentical, stress redistribution takes place in them under the action of applied stress in order to maintain same strain in all the layers. In addition, variable residual stresses are generated in the materials, during curing of the laminate, due to their different stiffness and coefficients of thermal expansions. The coefficients of thermal expansion of the laminate in longitudinal $(y)$ direction, $\alpha_{\mathrm{ll}}$, and in transverse $(x)$ direction, $\alpha_{\mathrm{t}}$, are found to be equal to $19.40 \times 10^{-6} \mathrm{C}^{-1}$ and $19.77 \times 10^{-6} \mathrm{C}^{-1}$, respectively, with the help of elementary formulations related to composites and laminates (Bhat and Narayanan 2014). Refer to Appendix 1. These coefficients are required to estimate the residual strain in each material layer that when superimposed with the strain developing in the laminate under maximum $(\max )$ applied tensile stress value in the fatigue cycle, $\sigma_{y \text {,applied,max }}$ results in maximum induced stress value in material layer, $m$, as $\sigma_{y, \text { induced,m,max }} \cdot \sigma_{y, \text { induced,m,max }}$ therefore equals the sum of redistributed stress, $\sigma_{y, \mathrm{ds}, \mathrm{m}, \max }$ and residual stress, $\sigma_{y, \mathrm{rs}, \mathrm{m}}$. Standard stress-strain constitutive equations of individual materials under plane stress condition, due to their small thickness, are employed to obtain their stiffness in the $x-y$ plane. Classical theory is used to determine the stiffness of the laminate. Both redistributed and residual stresses in materials along the $z$ direction are considered to be negligible. Stress state around crack tips in aluminum alloy layers further deviates from

Table 1 Properties of materials used in Glare

\begin{tabular}{|c|c|c|c|}
\hline Property & $\begin{array}{l}\text { Aluminum } \\
\text { 2014-T6 alloy (al) }\end{array}$ & $\begin{array}{l}\text { E-glass } \\
\text { fiber (f) }\end{array}$ & $\begin{array}{l}\text { Epoxy } \\
\text { resin }(r)\end{array}$ \\
\hline Modulus of elasticity $(E), \mathrm{MPa}$ & $72,000.0$ & $71,000.0$ & $3,500.0$ \\
\hline Shear modulus $(\mu), \mathrm{MPa}$ & $27,060.0$ & $29,700.0$ & $1,250.0$ \\
\hline Poisson's ratio $(U)$ & 0.33 & $0.22^{*}$ & 0.33 \\
\hline Yield strength (Y), MPa & 372.0 & - & - \\
\hline Ultimate tensile strength, $\mathrm{MPa}$ & 415.0 & $3,450.0$ & 60 \\
\hline Percent elongation & 8.0 & 4.8 & 4.0 \\
\hline $\begin{array}{l}\text { Coefficient of thermal } \\
\text { expansion }(a), C^{-1}\end{array}$ & $23 \times 10^{-6}$ & $5.0 \times 10^{-6}$ & $57.5 \times 10^{-6}$ \\
\hline Density, $\mathrm{g} / \mathrm{cc}$ & 2.71 & 2.45 & 1.54 \\
\hline $\begin{array}{l}\text { Plane strain fracture toughness } \\
\left(K_{1}\right), \mathrm{MPa} \sqrt{\mathrm{m}}\end{array}$ & 14.0 to 20.0 & 4.0 to 5.0 & 0.5 to 0.7 \\
\hline
\end{tabular}

The asterisk denotes a major value. induced stress due to bridging of load over cracks towards stronger fibers, commonly referred to as fiber bridging. Fiber bridging generates closing compressive stress in aluminum alloy layers that diminishes tensile stress fields around crack tips thereby shielding them.

\section{Theoretical aspects}

Since the cracks nucleate and grow in soft aluminum alloy layers of the laminate, different forms of stress intensity parameters are found in the laminate by using stress values in aluminum alloy layers. As discussed in the 'Glare details' section, the redistribution of applied stress and presence of residual stress in aluminum alloy layers cause the induced stress intensity parameter, $K_{\text {induced }}$, to differ from the applied value, $K_{\text {applied }}$. Further, due to fiber bridging in the laminate, the crack tip stress intensity parameter, $K_{\text {tip }}$, also deviates from $K_{\text {induced }} . K_{\text {tip }}$ is found by employing numerical or theoretical methodologies described elsewhere (Bhat and Narayanan 2014, pp. $157-160)$. However, in the present work, only $K_{\text {applied }}$ and $K_{\text {induced }}$ are used as characterizing parameters that, with the help of available experimental data, are found to be adequate to quantify the effect of fiber bridging in the laminates by comparing their fatigue behavior with that of plain aluminum alloy specimens.

The following conventional equations are employed to obtain various forms of cyclic stress intensity parameter, $\Delta K$, in laminate with edge crack of length, $c$, in aluminum layer under plane stress condition in highcycle regime where principles of linear elastic fracture mechanics (LEFM) are valid:

(i) Using applied stress value in the fatigue cycle as follows:

$$
\Delta K_{\text {applied }}=\left[\sigma_{y, \text { applied, } \max } \times(1-R)\right] \times \sqrt{\pi c} \times \mathrm{CF} \times U
$$

where $U$ is crack closure ratio and stress ratio, and

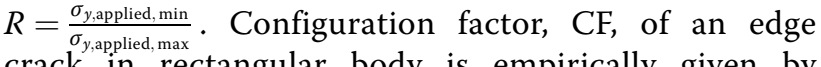
crack in rectangular body is empirically given by $\mathrm{CF}=\left[1.12-0.23 \frac{c}{w}+10.55\left(\frac{c}{w}\right)^{2}-21.72\left(\frac{c}{w}\right)^{3}+30.39\left(\frac{c}{w}\right)^{4}\right]^{7}$ (Kumar 2009). The expression is used in the present work, albeit with slight inaccuracy, even when the ratio $\frac{c}{w}$ exceeds 0.7 .

At laminate fracture when $c=c_{\otimes}$,

$$
\Delta K_{\text {applied }}=\Delta K_{\mathrm{C}, \text { applied }}
$$


(ii) Refer to Figure 2a). Using induced stress value in aluminum alloy layer as follows:

$$
\begin{aligned}
\Delta K_{\text {induced }}= & {\left[\left(\sigma_{y, d s, a l, \text { max }}+\sigma_{y, r s, a l}\right)-\left(R \times \sigma_{y, d s, a l, \text { max }}\right.\right.} \\
& \left.\left.+\sigma_{y, r s, a l}\right)\right] \times \sqrt{\pi c} \times \mathrm{CF} \times U
\end{aligned}
$$

where $\sigma_{y, \mathrm{ds}, \mathrm{al}, \max }$ and $\sigma_{y, \mathrm{rs}, \mathrm{al}}$ are redistributed and residual stress in load line, $y$, direction in aluminum alloy layer. Since $\sigma_{y, \mathrm{rs}, \mathrm{al}}$ is tensile (+ve) that makes the term $\left(R \times \sigma_{y \text {, ds, }}\right.$ al,max $\left.+\sigma_{y, \text { rs,al }}\right)$ greater than zero (tensile), the effect of residual stress is nullified. $\Delta K_{\text {induced }}$ reduces to

$$
\begin{aligned}
& \Delta K_{\text {induced }}=\left[\sigma_{y, d s, a l, \max }(1-R)\right] \times \sqrt{\pi c} \times C F \times U \\
& \Delta K_{\text {induced }}=\Delta K_{\mathrm{C}, \text { induced }}
\end{aligned}
$$

when

$$
c=c_{\otimes}
$$

(iii) Refer to Figure 2b. The value of $\Delta K$ in plain aluminum alloy specimen $(\mathrm{P})$ is obtained from the applied stress value only due to the absence of load redistribution and residual stress in the specimen. Since tensile residual stress in aluminum layers of the laminate does not influence its fatigue properties, maximum stress, $\sigma_{y \text {,applied,max }}$ in fatigue cycles applied over plain specimens is kept equal to $\sigma_{y, \mathrm{ds}, \mathrm{al} \text {,max }}$ to simulate identical fatigue load in plain specimens as that in aluminum alloy layers of the laminates. $\Delta K$ in plain specimen is written as follows:

$$
\begin{aligned}
\Delta K_{\mathrm{P}}= & {\left[\sigma_{y, \text { applied,max }} \times(1-R)\right] \times \sqrt{\pi c} \times \mathrm{CF} } \\
& \times U \\
= & {\left[\sigma_{y, d s, \text { al,max }} \times(1-R)\right] \times \sqrt{\pi c} \times \mathrm{CF} \times U } \\
\Delta K_{\mathrm{P}}= & \Delta K_{\mathrm{C}, \mathrm{al}}
\end{aligned}
$$

when

$$
c=c_{\otimes}
$$

$U$ of aluminum alloy in all the above equations is taken as $0.5+0.4 \mathrm{R}$ (Elber 1976).

\section{Experimental method}

Two-millimeter thick 2014-T6 aluminum alloy sheets were cold rolled to reduce their thickness to acceptable level that was followed by their suitable heat treatment to restore the T6 state of the aluminum alloy. Prepregs were manually prepared and stored in controlled environment prior to use. At the time of laminate fabrication, an assembly of three aluminum alloy sheets alternately reinforced with two prepregs was loaded in a hydraulic a)

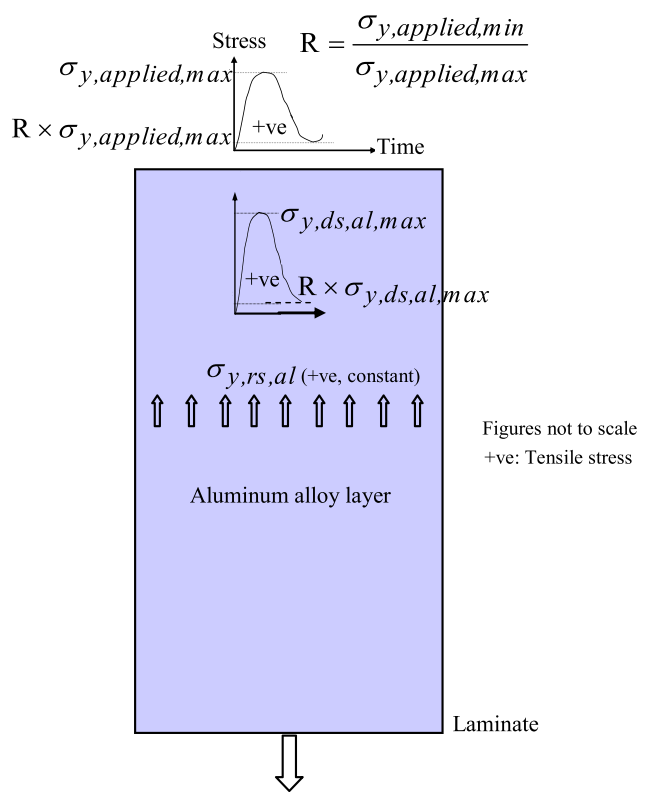

b)

$\sigma_{y, \text { applied,max }}=\sigma_{y, d s, a l, \max }$

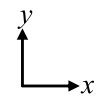

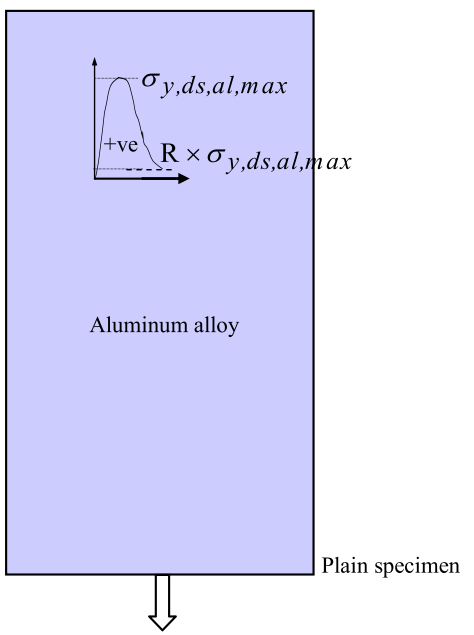

Figure 2 Details of load over (a) aluminum alloy layer of laminate and (b) plain aluminum alloy specimen. 
press preheated to $90^{\circ} \mathrm{C}$. A pressure of 10 bar was gradually applied over the assembly. The temperature was raised to $160^{\circ} \mathrm{C}$, and the assembly was cured at that temperature for $3 \mathrm{~h}$. After curing, the press was cooled to room temperature followed by the release of pressure. The laminate assembly was taken out from the press and visually inspected for defects. The thickness data of all the laminates were recorded. The achieved/measured dimensional range of the laminate was as follows: $t_{\mathrm{al}}=0.35$ to $0.58 \mathrm{~mm}, d=2.2$ to $2.9 \mathrm{~mm}, l=200$ to $202 \mathrm{~mm}$, and $w=50.35$ to $51.35 \mathrm{~mm}$. Deviations from the desired values provided in the 'Glare details' section, especially in laminate thickness, were attributed to (i) difficulty in maintaining precise control over thickness of aluminum alloy sheets during rolling, (ii) manual application of resin over fiber cloth during the preparation of prepregs, and (iii) effect of high temperature and bonding pressure on the dimensions of the material layers during curing of the laminate. The dimensional difference between the laminates however has not been included in the computations at Appendix 1 that are based on standard dimensions.

Before proceeding with fatigue tests, standard specimens were machined out from laminates for tensile, flexural, and shear strength measurement to check the mechanical properties of the laminates. Several specimens were used in each test to obtain reliable results. The results, provided in Table 2, displayed good consistency, thereby validating the test data and also the fabrication procedure of laminates. Optical microscopy was undertaken on external aluminum alloy layers of the laminate to check the effects of high curing temperature on their micro-structure. One percent HF solution was used as an etchant. The microstructure confirmed fine dispersion of $\mathrm{Cu}-\mathrm{Al}_{2}$ and $\mathrm{Al}-\mathrm{Si}$ particles in the matrix of the aluminum solid solution without development of new detrimental products.

Refer to Figure 3. Glare laminates, with starter Mode I edge notches of $1.5-\mathrm{mm}$ size machined across all the material layers, held at opposite ends of a hydraulic test rig with gripping pressure of $5 \mathrm{MPa}$ were subjected to tensile-tensile fatigue cycles at 25 cycles/s in the $y$ direction until they fractured under the following load and environmental conditions: (i) $\sigma_{y \text {,applied,max }}$ value of $75 \mathrm{MPa}$ in fatigue cycle to ensure controlled crack growth rates for effective measurement and recording purpose

(ii) Stress ratio, $R$, of $0.1,0.3$, and 0.5 (all $+\mathrm{ve})$. The ratio was kept constant during each test to maintain constant amplitude of load

(iii) Test environments namely ambient (A), aqueous $(\mathrm{M})$, and corrosive (S)

Aqueous and corrosive environments were simulated by immersing the laminates in respective fluids, i.e., plain water (M) and salt + water solution (S) for sufficient period of time followed by spraying fluids over the laminates during fatigue tests. As expected, fatigue cracks nucleated in soft aluminum alloy layers, but not in strong fibers of prepregs in all the test conditions. Refer to Figure 4 . The cracks were found to grow simultaneously in all three aluminum alloy layers of some laminates (case I, Figure 4a), whereas in only one external aluminum alloy layer of the remaining laminates (case II, Figure 4b). This phenomenon, in general, did not exhibit any specific correlation with the operational parameters except the development of case I in aqueous environment at all the values of $R$ and the development of case II in ambient environment at $R$ of 0.3. Delaminations did not develop in both cases as no interfacial crack growth was observed in the transverse direction at aluminum-fiber interfaces. This was also confirmed by fractography (SEM) images of the fatigue surfaces of aluminum alloy layers of fractured laminates; few such images are displayed in highly magnified form in Figure 5. The size, $b$, of the interfacial crack was negligible in comparison with the size, $c$, of mode I cracks, thereby supporting the absence of delaminations.

Crack lengths, $c$, were measured. Corresponding number of cycles, $N$, was recorded. Crack growth rate, $\frac{d c}{d N}$, at each crack length was computed. Values of $c_{\otimes}$ and total cycles, $N_{\otimes}$, consumed in crack initiation at the notch tip and subsequent propagation until fracture of each laminate were noted, with $N_{\otimes}$ being the measure of fatigue life. $\frac{d c}{d N}$ values were also obtained in the notched plain 2014-T6 aerospace aluminum alloy specimens with dimensions nearly similar as those of the laminates for comparative analysis of their fatigue behavior with those of the laminates. These specimens were subjected to tensile-tensile fatigue cycles with $R$ of 0.1 in ambient environment alone. As discussed

Table 2 Mechanical properties of Glare

\begin{tabular}{lccccc}
\hline Property & Specimen 1 & Specimen 2 & Specimen 3 & Mean & Standard deviation \\
\hline Yield strength $(\mathrm{MPa})$ & 269.7 & 273.05 & 277.28 & 273.34 & 3.79 \\
Ultimate tensile strength $(\mathrm{MPa})$ & 360.3 & 365.13 & 370.62 & 365.35 & 5.163 \\
Flexural strength $(\mathrm{MPa})$ & 728.8 & 763.0 & 730.1 & 740.63 & 19.381 \\
Shear strength $(\mathrm{MPa})$ & 37.79 & 40.04 & 42.74 & 40.19 & 2.478 \\
\hline
\end{tabular}




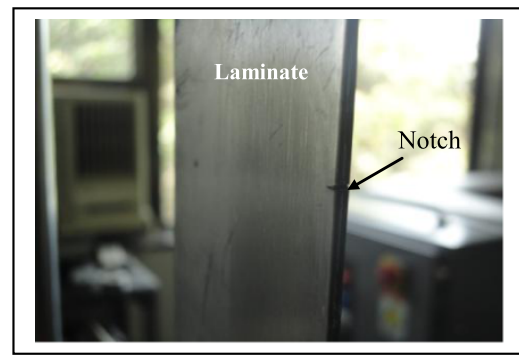

a)

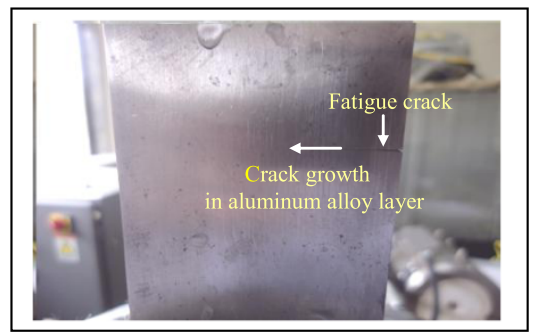

c)

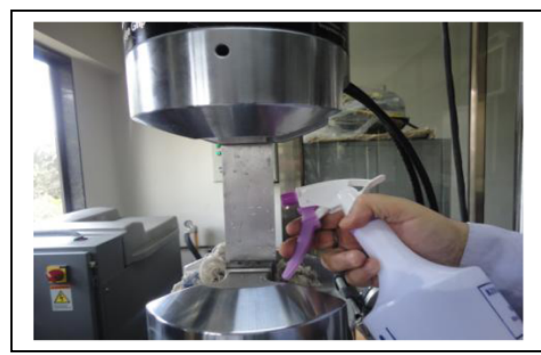

b)

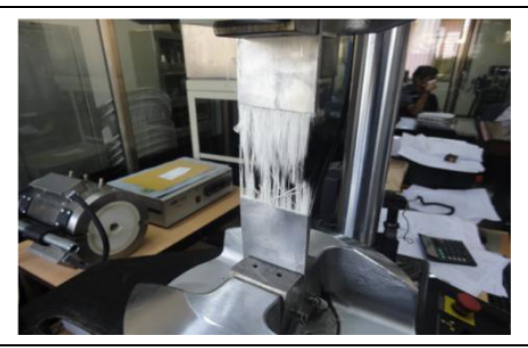

d)

Figure 3 Fatigue test arrangement. (a) Starter notch in laminate, (b) simulation of moist and corrosive environments during test, (c) fatigue crack in laminate, and $(\mathbf{d})$ fractured laminate.

in the 'Theoretical aspects' section, the maximum stress in fatigue cycles applied over such specimens was fixed at 97.45 MPa. Refer to Appendix 1. The value of redistributed stress, $\sigma_{y, \mathrm{ds}, \mathrm{al} \text {,max }}$ in aluminum alloy layers of the laminate when it experiences peak applied stress of $75 \mathrm{MPa}$ during the fatigue cycle is $97.45 \mathrm{MPa}$.

\section{Results and discussion}

The values of $\frac{\sigma_{y, \text { induced, al max }}}{Y_{\text {al }}}$ in the laminates and $\frac{\sigma_{y, d s, a l, m a x}}{Y_{\text {al }}}$ in the plain aluminum alloy specimens are less than 0.5 that indicate LEFM regime and high-cycle fatigue condition ( $Y_{\text {al }}$ representing yield strength of aluminum alloy). The value around crack tips in the laminates further drops with the onset of fiber bridging, thereby promoting high-cycle condition. Refer to Table 3 . High values of $N_{\otimes}$ recorded in the laminates and in plain specimens also support high-cycle conditions. So, the use of parameter $\Delta K$ is valid. Fulfillment of equations $t_{\mathrm{al}}<2.5$ $\left(\frac{\Delta K_{\text {induced }}}{2 Y_{\text {al }}}\right)^{2}$ in laminates and $d<2.5\left(\frac{\Delta K_{\mathrm{p}}}{2 Y_{\mathrm{al}}}\right)^{2}$ in plain a)

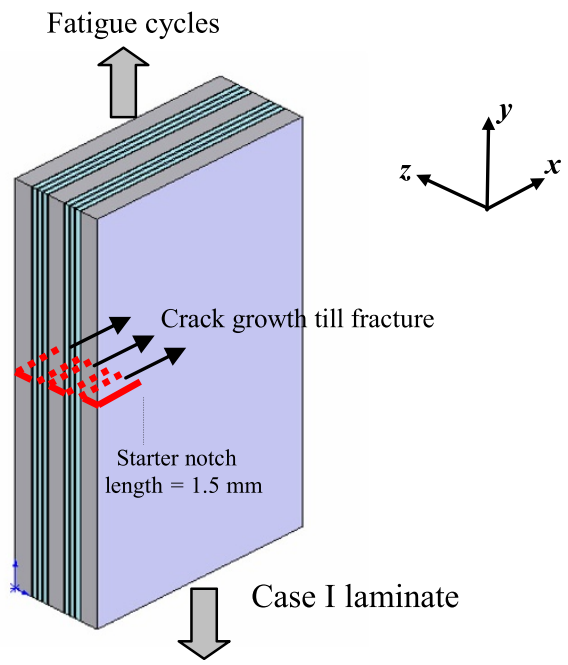

b)

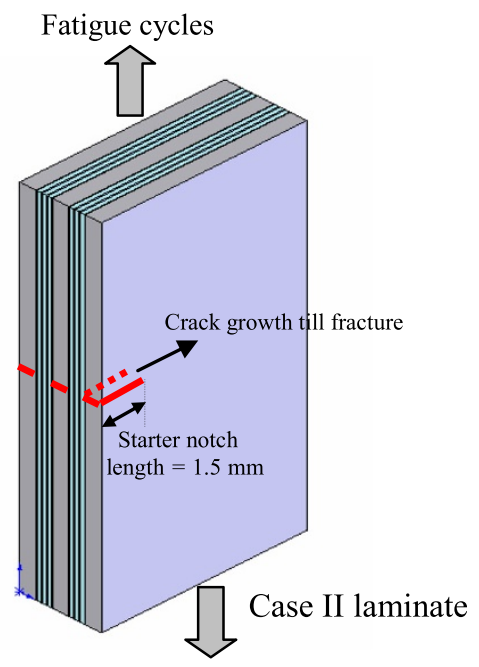

Figure 4 Schematic of fatigue crack growth in (a) case I and (b) case II laminates. 


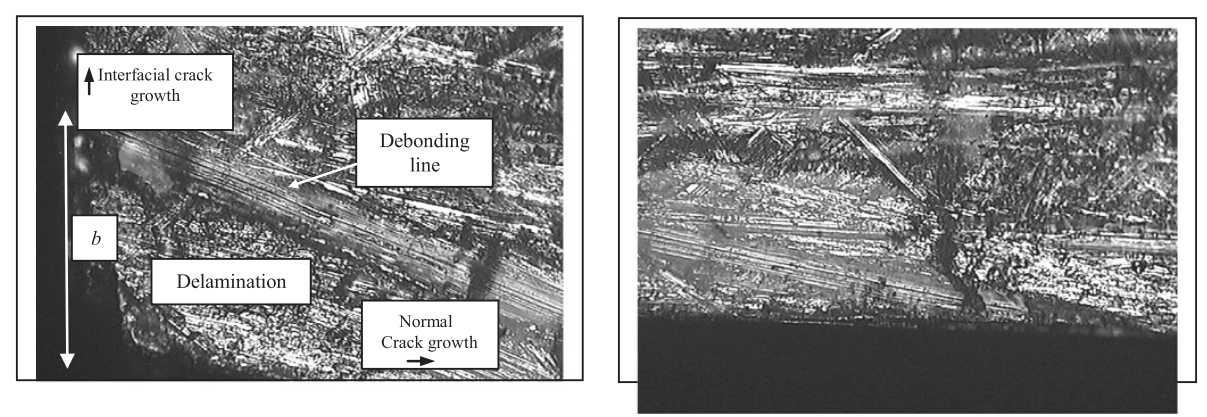

Figure 5 Fractographs of fatigue surfaces of aluminum alloy layers in Glare. a) Fractograph 1) b) Fractograph 2).

specimens at nearly all crack lengths confirms plane stress condition from fatigue point of view. Hence, the use of parameter $\Delta K_{\mathrm{C}}$ is justified. All forms of $\Delta K$ are computed at increasing crack lengths using Equations 1 to 7 . The results of the laminates in all test environments are as follows:

\section{Case I laminates}

The data of case I laminates under different $R \mathrm{~s}$ are presented in the form of series 1 to 9: series 1 to 4 in ambient environment, series 5 to 7 in aqueous environment, and series 8 to 9 in corrosive environment.

Table 3 Dimensional data and fatigue results of Glare laminates and plain aluminum alloy specimens

\begin{tabular}{lcccccc}
\hline Series & $\boldsymbol{w}(\mathbf{m m})$ & $\boldsymbol{d}(\mathbf{m m})$ & Environment & $\boldsymbol{R}$ & $\boldsymbol{c}_{\otimes}(\mathbf{m m})$ & $\boldsymbol{N}_{\otimes}$ (cycles) \\
\hline Glare laminates & & & & & \\
Case I & & & & & & \\
1 & 50.55 & 2.85 & $\mathrm{~A}$ & 0.1 & 28 & 46,328 \\
2 & 50.7 & 2.5 & $\mathrm{~A}$ & 0.5 & 34 & 115,000 \\
3 & 50.8 & 2.2 & $\mathrm{~A}$ & 0.5 & 35 & 126,270 \\
4 & 50.55 & 2.55 & $\mathrm{~A}$ & 0.5 & 15 & 58,725 \\
5 & 50.5 & 2.6 & $\mathrm{M}$ & 0.1 & 34 & 29,163 \\
6 & 50.7 & 2.48 & $\mathrm{M}$ & 0.3 & 35 & 22,473 \\
7 & 51.35 & 2.35 & $\mathrm{M}$ & 0.5 & 30 & 193,503 \\
8 & 51.1 & 2.9 & $\mathrm{~S}$ & 0.1 & 13 & 5,157 \\
9 & 50.35 & 2.6 & $\mathrm{~S}$ & 0.3 & 9 & 8,671 \\
Case II & & & & & & \\
1 & 50.4 & 2.3 & $\mathrm{~A}$ & 0.1 & 32 & 63,697 \\
2 & 50.5 & 2.55 & $\mathrm{~S}$ & 0.1 & 30 & 52,476 \\
3 & 50.45 & 2.6 & $\mathrm{~A}$ & 0.3 & 40 & 66,219 \\
4 & 50.4 & 2.6 & $\mathrm{~A}$ & 0.3 & 45 & 81,212 \\
5 & 50.45 & 2.2 & $\mathrm{~S}$ & 0.5 & 26 & 48,717 \\
Plain aluminum $2014-\mathrm{T} 6$ alloy specimens & & & \\
P1 & 36.3 & 1.6 & $\mathrm{~A}$ & 0.1 & 15 & 16,575 \\
P2 & 50.9 & 1.55 & $\mathrm{~A}$ & 0.1 & 20 & 37,225 \\
\hline
\end{tabular}

Types of test environments: $A$, ambient; $M$, aqueous; $S$, corrosive.
Refer to Figure $6 \mathrm{a}$. The value on the vertical axis of data point at the extreme right in each curve represents $N_{\otimes}$. (i) In ambient environment, the number of cycles, $N$, needed for crack growth increases with the increase in $R$. $N_{\otimes}$ too increases with $R$. (ii) In aqueous environment, $N$ shows mixed results with increase in $R$. At lower $R, N$ and $N_{\otimes}$ decrease with the increase in $R$, whereas at higher $R, N$ and $N_{\otimes}$ increase with the increase in $R$. (iii) In corrosive environment, $N$ and $N_{\otimes}$ increase slightly with the increase in $R$.

Refer Figure 6b,c,d. (i) In ambient environment, increase in stress ratio, $R$, dips $\frac{d c}{d N}$ unlike in homogeneous and some composite materials where increase in $R$ reduces crack closure causing increase in $\frac{d c}{d N}$. This is attributed to substantial influence of reduction in applied and induced values of cyclic stress intensity parameter due to increase in $R$ in comparison with corresponding reduction in crack closure. Moreover, closure effects in the laminates do not appear to be dominant due to crack tip shielding caused by fiber bridging that results in minimal crack tip plasticity. Maximum $\frac{d c}{d N}$ at $R$ of 0.1 is $0.015 \mathrm{~mm} /$ cycle, while the corresponding value at $R$ of 0.5 is $0.00347 \mathrm{~mm} /$ cycle. Using the applied value, the $\max -$ imum fracture toughness value of laminate, $\Delta K_{\mathrm{C} \text {,applied }}$, is $49.74 \mathrm{MPa} \sqrt{\mathrm{m}}$ at $R$ of $0.5(U=0.7)$. Likewise, using induced stress value in aluminum layers, $\Delta K_{\mathrm{C} \text {,induced }}$ is 64.6 $\mathrm{MPa} \sqrt{\mathrm{m}}$. (ii) In aqueous environment, increase in $R$ again dips $\frac{d c}{d N}$. Maximum $\frac{d c}{d N}$ at $R$ of 0.1 is $0.028 \mathrm{~mm} / \mathrm{cycle}$, while the corresponding value at $R$ of 0.5 is $0.00245 \mathrm{~mm} /$ cycle. In comparison with ambient environment at same values of $R$ and stress intensity parameter, $\frac{d c}{d N}$ values are higher at lower $R$ and lower at higher $R$. Laminate fracture toughness values also show an upward trend. The maximum value of $\Delta K_{\text {C,applied }}$ is $63.9 \mathrm{MPa} \sqrt{\mathrm{m}}$ at $R$ of 0.1 $(U=0.54)$. The corresponding induced value is $83.0 \mathrm{MPa}$ $\sqrt{\mathrm{m}}$. (iii) In corrosive (salt) environment, increase in $R$ augments $\frac{d c}{d N}$. The maximum $\frac{d c}{d N}$ at $R$ of 0.1 is $0.01 \mathrm{~mm} /$ cycle, while the corresponding value at $R$ of 0.3 is $0.02 \mathrm{~mm} /$ cycle. In comparison with ambient environment 


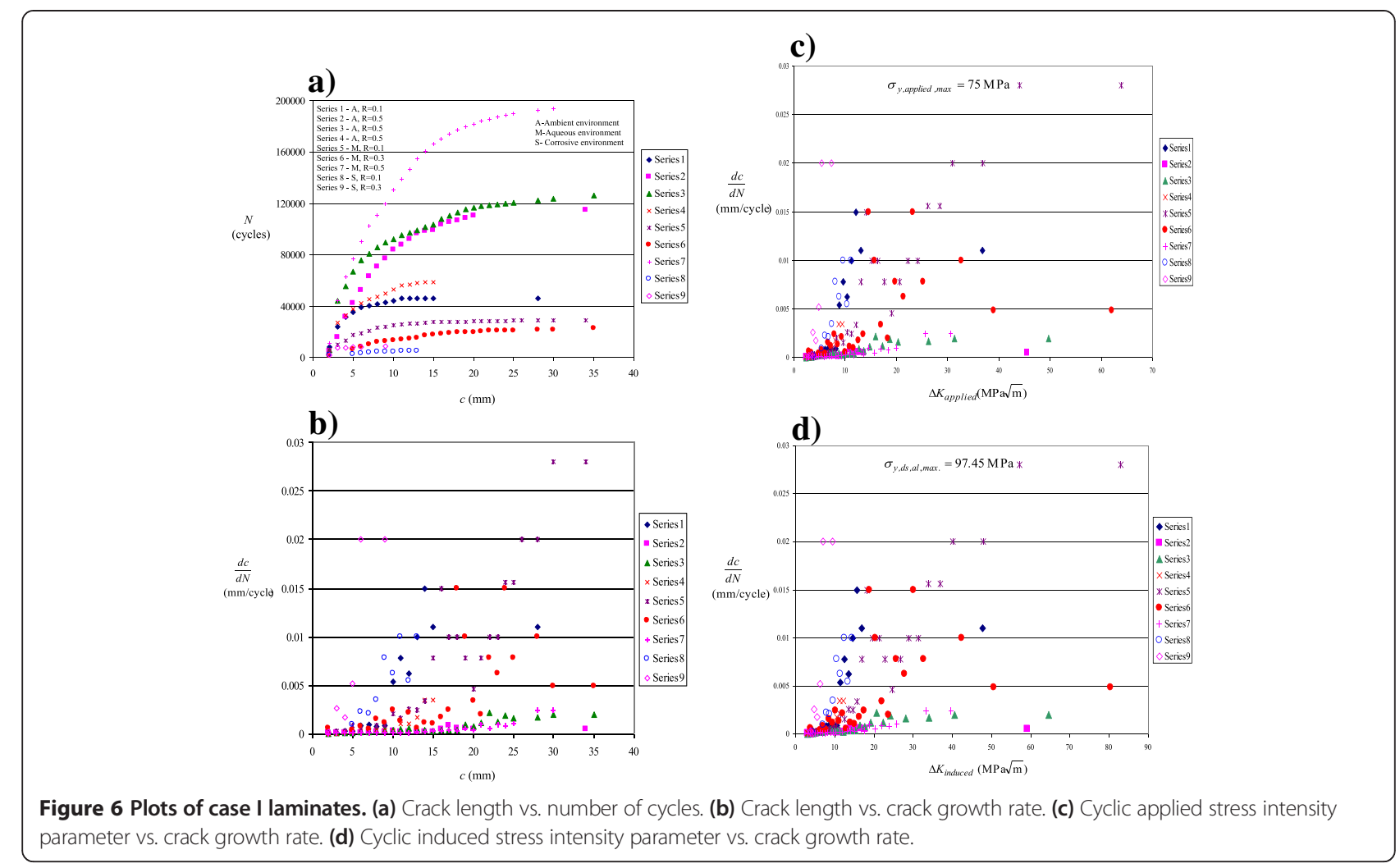

at same values of $R$ and stress intensity parameter, $\frac{d c}{d N}$ values are more at both lower and higher values of $R$. In comparison with aqueous environment at same values of $R$ and stress intensity parameter, $\frac{d c}{d N}$ values are also more at both lower and higher values of $R$. Laminate fracture toughness values are much less than those in ambient and aqueous environments. The maximum value of $\Delta K_{\mathrm{C} \text {,applied }}$ is $11.15 \mathrm{MPa} \sqrt{\mathrm{m}}$ at $R$ of $0.1(U=0.54)$. The corresponding induced value is $14.48 \mathrm{MPa} \sqrt{\mathrm{m}}$.

\section{Case II laminates}

The data of case II laminates under different $R$ s are presented in the form of series 1 to 5 : series 1,3 , and 4 in ambient environment, and series 2 and 5 in corrosive environment. Refer to Figure 7a. (i) In ambient environment, $N$ and $N_{\otimes}$ increase with increase in $R$. (ii) In corrosive environment, $N$ and $N_{\otimes}$ decrease with increase in $R$.

Refer to Figure 7b,c,d. (i) In ambient environment, increase in $R$ dips $\frac{d c}{d N}$, although the effect is not as high as in case I laminates. The maximum $\frac{d c}{d N}$ at $R$ of 0.1 is $0.01 \mathrm{~mm} /$ cycle, while the corresponding value at $R$ of 0.3 is $0.0075 \mathrm{~mm} /$ cycle. The maximum value of $\Delta K_{\mathrm{C} \text {,applied }}$ is 161.2 $\mathrm{MPa} \sqrt{\mathrm{m}}$ at $R$ of $0.3(U=0.62)$. The maximum induced value, $\Delta K_{\mathrm{C} \text {,induced }}$, even reaches up to $209.4 \mathrm{MPa} \sqrt{\mathrm{m}}$. In comparison with case I laminates in the same environment, the maximum laminate fracture toughness values are higher, and the maximum $\frac{d c}{d N}$ values are of nearly similar magnitudes. (ii) In aqueous environment, crack did not grow in one but in all the aluminum layers, which is already discussed in case I laminate. (iii) In corrosive (salt) environment, the increase in $R$ augments $\frac{d c}{d N}$. The maximum $\frac{d c}{d N}$ at $R$ of 0.1 is $0.0028 \mathrm{~mm} /$ cycle, while the corresponding value at $R$ of 0.5 is $0.0154 \mathrm{~mm} /$ cycle. In comparison with the ambient environment at same values of $R$ and stress intensity parameter, $\frac{d c}{d N}$ values are smaller at lower $R$ but more at higher $R$. The data for comparison with aqueous environment are not available. The maximum value of $\Delta K_{\mathrm{C} \text {,applied }}$ is $44.07 \mathrm{MPa} \sqrt{\mathrm{m}}$ at $R$ of $0.1(U=0.54)$. The corresponding induced value is $57.26 \mathrm{MPa} \sqrt{\mathrm{m}}$. In comparison with case I laminate in same environment, the maximum fracture toughness values are higher, and the maximum $\frac{d c}{d N}$ values are lesser.

\section{Comparison between performance of laminates and plain aluminum alloy specimens}

Refer to Figure 8a,b and Table 3. Since plain aluminum alloy specimens, series P1 and P2, exhibited crack growth on both their sides, their behavior is compared with series 1 of case I laminates that was tested under similar conditions, i.e., $R$ of 0.1 in ambient environment. The values of $N$ and $N_{\otimes}$ in the plain specimens are lesser than those in case I laminate. Opposite holds good for $\frac{d c}{d N}$.

The values of $\Delta K_{\mathrm{C} \text {,al }}$ are obtained as $22.40 \mathrm{MPa} \sqrt{\mathrm{m}}$ in series $\mathrm{P} 1$ and $24.50 \mathrm{MPa} \sqrt{\mathrm{m}}$ in series P2. Deviation in 
a)

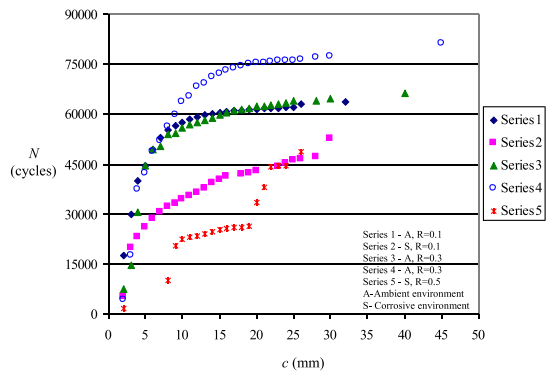

b)

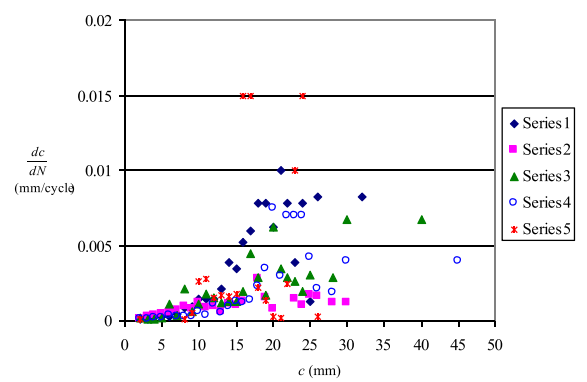

c)

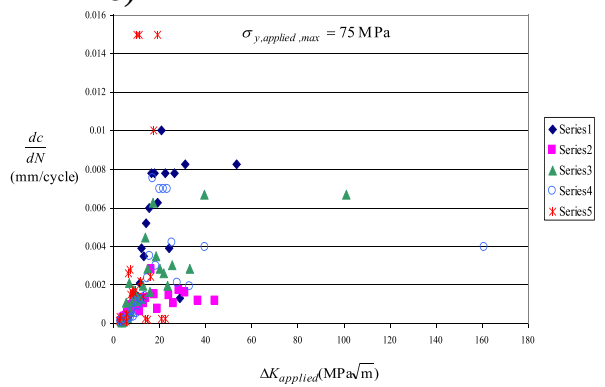

d)

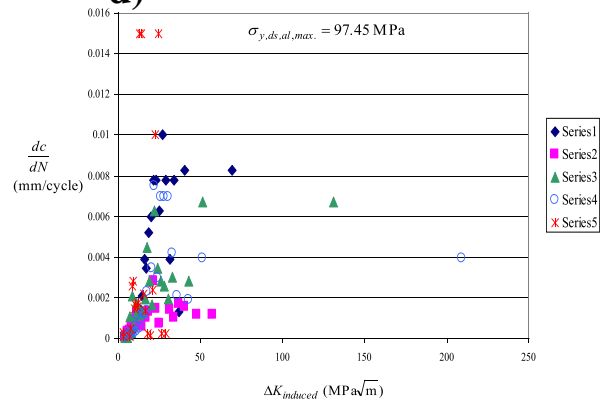

Figure 7 Plots of case II laminates. (a) Crack length vs. number of cycles. (b) Crack length vs. crack growth rate. (c) Cyclic applied stress intensity parameter vs. crack growth rate. (d) Cyclic induced stress intensity parameter vs. crack growth rate.

\section{a)}

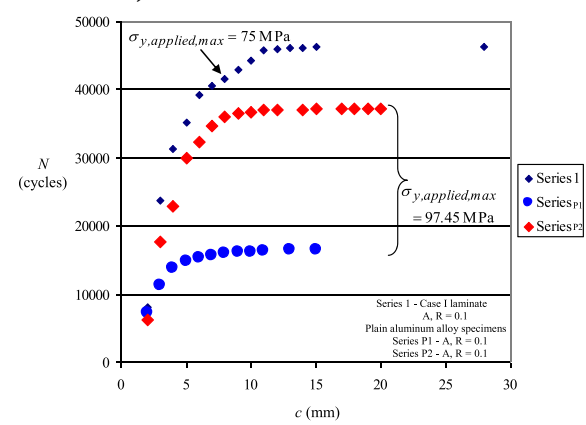

b)

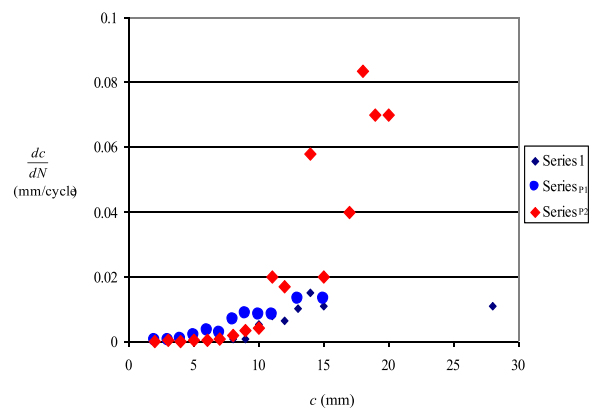

c)

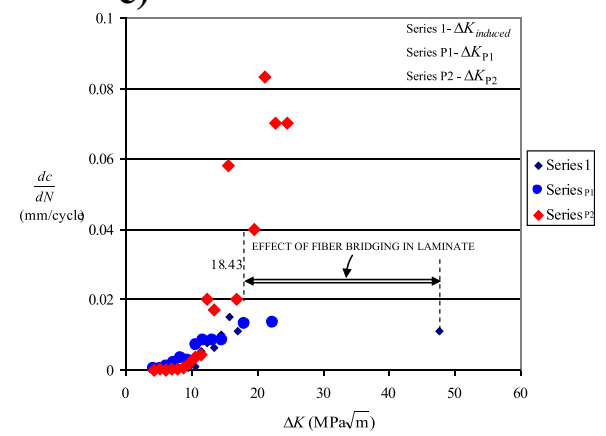

d)

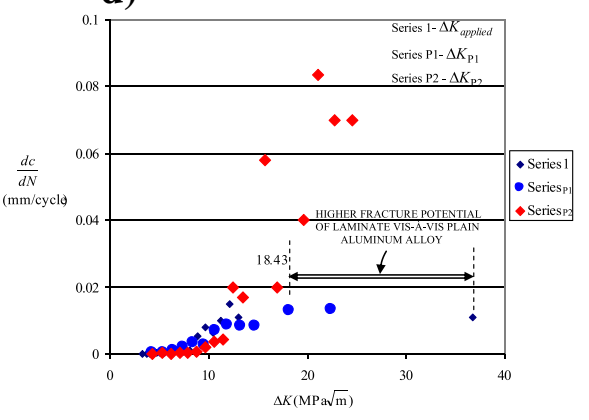

Figure 8 Comparative plots between plain aluminum alloy specimens and case I laminate. a) Crack length vs. number of cycles in laminate (Series 1) and plain specimens b) Crack length vs. crack growth rate in laminate (Series 1) and plain specimens c) Cyclic induced stress intensity parameter vs. crack growth rate in laminate (Series 1) and plain specimens $\mathbf{d}$ ) Cyclic applied stress intensity parameter vs. crack growth rate in laminate (Series 1) and plain specimens. 
values is due to slight difference in thickness of specimens in stated series. Cyclic plane strain fracture toughness of plain specimens, $\Delta K_{\mathrm{IC}, \mathrm{a}}$, is found by using well-known expression (Irwin 1967) that links plane stress and plane strain values as follows:

$$
\Delta K_{\mathrm{C}, \mathrm{al}}=\Delta K_{\mathrm{IC}, \mathrm{al}}\left[1+\frac{1.4}{d^{2}}\left(\frac{\Delta K_{\mathrm{IC}, \mathrm{al}}}{Y_{\mathrm{al}}}\right)^{4}\right]^{1 / 2}
$$

As the thickness of plain specimens is different than that of series 1 laminate, their $\Delta K_{\mathrm{C}, \mathrm{al}, *}$ values corresponding to the thickness of the laminate, i.e., $2.85 \mathrm{~mm}$, is determined by using Equation $8 . \Delta K_{\mathrm{IC}, \mathrm{al}}$, is first obtained using $\Delta K_{\mathrm{C} \text {,al }}$ with original specimen thickness that is followed by recomputation of $\Delta K_{\mathrm{C}, \mathrm{al}, *}$ from the same equation with changed specimen thickness. The results of the plain aluminum alloy specimens are consolidated as follows:

Series P1: specimen thickness, $d=1.6 \mathrm{~mm}, w=36.3 \mathrm{~mm}$, $c_{\otimes}=15 \mathrm{~mm}, \Delta K_{\mathrm{C}, \mathrm{al}}=22.40 \mathrm{MPa} \sqrt{\mathrm{m}}(\mathrm{CF}=2.179) ;$ $\Delta K_{\mathrm{IC}, \mathrm{al}}=14.69 \mathrm{MPa} \sqrt{\mathrm{m}}$; for thickness of $2.85 \mathrm{~mm}$, $\Delta K_{\mathrm{C}, \mathrm{al}, *}=17.49 \mathrm{MPa} \sqrt{\mathrm{m}}$.

Series P2: Specimen thickness, $d=1.55 \mathrm{~mm}, w=50.9 \mathrm{~mm}$, $c_{\otimes}=20 \mathrm{~mm} \quad \Delta K_{\mathrm{C}, \mathrm{al}}=24.50 \mathrm{MPa} \sqrt{\mathrm{m}} \quad(\mathrm{CF}=2.065) ;$ $\Delta K_{\mathrm{IC}, \mathrm{al}}=15.17 \mathrm{MPa} \sqrt{\mathrm{m}}$; for thickness of $2.85 \mathrm{~mm}$, $\Delta K_{\mathrm{C}, \mathrm{a}, *}=18.43 \mathrm{MPa} \sqrt{\mathrm{m}}$.

Quasi-static $K_{\mathrm{IC}, \text { al }}$ values of plain specimens, equal to $\frac{\Delta K_{\mathrm{IC}, \mathrm{al}}}{0.9}$, are 16.32 $\mathrm{MPa} \sqrt{\mathrm{m}}$ (series P1) and 16.85 $\mathrm{MPa} \sqrt{\mathrm{m}}$ (series P2) that lie within the expected range of plane strain fracture toughness of 2014-T6 aluminum alloy available in Table 1. This authenticates the quality of aluminum alloy used as well as the accuracy of fatigue test equipment.

Refer to Figure 8c. To quantify the effect of fiber bridging in laminate vis-à-vis plain aluminum alloy specimen, induced cyclic stress intensity parameter values in the laminate are employed for comparison. $\Delta K_{\mathrm{C} \text {,induced }}$ of series 1 laminate is $47.72 \mathrm{MPa} \sqrt{\mathrm{m}}$. On the other hand, the maximum value of $\Delta K_{\mathrm{C}, \mathrm{al}, *}$ in the plain specimen (series P2) is $18.43 \mathrm{MPa} \sqrt{\mathrm{m}}$ which is much less than that of series 1 laminate. The values of $N_{\otimes}$ in plain specimens are 16,575 cycles (series P1) and 37,225 cycles (series P2), whereas it is 46,328 cycles for series 1 laminate. At other values of $R$ in ambient environment, the values of $N_{\otimes}$ of the laminates are much more than those of the plain specimens. The maximum $\frac{d c}{d N}$ of the plain specimens are $0.013 \mathrm{~mm} /$ cycle (series P1) and $0.083 \mathrm{~mm} /$ cycle (series P2) which are nearly identical or higher than that of $0.015 \mathrm{~mm} /$ cycle of the series 1 laminate. The values of $c_{\otimes}$ in the plain specimens are $15 \mathrm{~mm}$ (series P1) and $20 \mathrm{~mm}$ (series P2) that are also less than $28 \mathrm{~mm}$ in series 1 laminate. These findings convincingly confirm the phenomenon of fiber bridging in the laminate that shields the crack tips in its aluminum alloy layers, thereby retarding fatigue crack growth rates and increasing critical crack lengths leading to enhanced fatigue life and cyclic fracture toughness values of the laminate in comparison with plain aluminum alloy specimens.

Refer to Figure 8d. To compare the fracture potential of Glare laminate vis-à-vis plain aluminum alloy specimen from commercial point of view, applied cyclic stress intensity parameter values in the laminate are used in order to disregard the effects of stress redistribution and residual stress in the laminate that are missing in the plain specimens. The maximum $\Delta K_{\mathrm{C} \text {,applied }}$ value of series 1 laminate is $36.75 \mathrm{MPa} \sqrt{\mathrm{m}}$ which too is higher than the maximum $\Delta K_{\mathrm{C}, \mathrm{al}, *}$ of $18.43 \mathrm{MPa} \sqrt{\mathrm{m}}$ in plain specimens, justifiably assuming that the $\Delta K_{\mathrm{P}}$ data of the plain specimens do not change significantly under fatigue cycles with peak stress value of $75 \mathrm{MPa}$ instead of 97.45 MPa. This observation substantiates higher fatigue and fracture potential of the laminate vis-à-vis plain aluminum alloy specimens under similar load and environmental conditions.

\section{Conclusions}

Notched Glare 4A-3/2 laminates comprising three thin 2014-T6 aerospace aluminum alloy layers alternately bonded and cured with two epoxy resin-impregnated Eglass fiber-based composite prepregs are tested under constant amplitude tensile-tensile fatigue cycles with positive stress ratios, $R$, of $0.1,0.3$, and 0.5 in ambient, aqueous, and corrosive (salt) environments. The maximum stress in the applied fatigue cycle is fixed at $75 \mathrm{MPa}$. The cracks grow simultaneously in all the aluminum layers of some laminates (case I), while in only one external aluminum layer of the remaining laminates (case II). No interfacial crack growth and delamination is observed at aluminum fiber interfaces in both cases. Notched plain 2014-T6 aerospace aluminum alloy specimens are also tested at $R$ of 0.1 in ambient environment under identical stress levels as in aluminum alloy layer of laminates for comparative analysis of their fatigue behavior with those of the laminates. Following generalized conclusions are drawn from the reported results:

(i) Increase in $R$ dips fatigue crack growth rate, $\frac{d c}{d N}$, in the laminates under ambient and aqueous environments, whereas it augments $\frac{d c}{d N}$ in corrosive (salt) environment. The trends hold good in both case I and case II laminates.

(ii) Fatigue lives of laminates, $N_{\otimes}$, change with environment. They are higher in ambient and aqueous environments and least in corrosive environment. Increase in $R$ enhances the fatigue life in both ambient and aqueous environments in case 
I and in ambient environment in case II laminates due to drop in $\frac{d c}{d N}$. In corrosive environment, $N_{\otimes}$ in case I laminates is found to increase with increase in $R$ which is contrary to expectations since $\frac{d c}{d N}$ increases with increase in $R$ in such an environment. This aberration is attributed to higher crack initiation life and reduced propagation life at higher $R$. In case II laminates under similar environment, the results are in line with the expectations. Also, at same $R$ in case I laminates, fatigue life in ambient environment is higher than in aqueous environment at lower $R$ and vice versa at higher $R$. This is due to higher $\frac{d c}{d N}$ values at lower $R$ and lesser $\frac{d c}{d N}$ values at higher $R$ in aqueous environment in comparison with that in ambient environment. Fatigue life in ambient environment is higher than that in corrosive environment at same $R$ in both case I and case II laminates.

(iii) Cyclic fracture toughness values of the laminates also change with environment. They are higher in aqueous and ambient environments and least in corrosive environment in both case I and case II laminates. In case I laminate, the values in ambient environment, in general, increase with increase in $R$. In aqueous environment, the values are higher at lower $R$ and lower at higher $R$. In corrosive environment, the values tend to drop with increase in $R$. Trends in case II laminates under ambient and corrosive environments are similar to as stated for case I laminates.

(iv) From fatigue and fracture point of view, the laminates can be employed in aqueous environments provided that persistent or excessive exposure to water does not degrade the quality of adhesive/resin between the aluminum alloy and fiber layers leading to their separation or reduction of the strength of fibers resulting in overall property degradation of the laminate. This aspect needs to be investigated separately. But fatigue and fracture behavior of the laminates clearly deteriorates in corrosive conditions, although the results in case II are better than those in case I. Such observations go against the use of laminates in corrosive environment.

(v) Fatigue lives and cyclic fracture toughness of laminates are convincingly more than those of plain aluminum alloy specimens that corroborates fiber bridging in the laminates, leading to their enhanced fatigue and fracture properties.

\section{Notations}

$b$ interfacial crack length

$c$ mode I crack length

CF configuration factor

$d$ thickness of laminate/plain specimen

$l$ laminate length $t$ thickness of material layer

$w$ laminate width

A ambient environment

$E$ modulus of elasticity

FML fiber metal laminate

$K$ stress intensity parameter

LEFM linear elastic fracture mechanics

$M$ aqueous environment

$\{\mathrm{M}\}$ stiffness matrix

$N$ number of fatigue cycles

$R$ stress ratio

$\mathrm{S}$ corrosive environment

$T$ temperature

$U$ closure ratio

$Y$ yield strength

$\frac{d c}{d N}$ crack growth rate

1 to 8 laminate series

\section{Symbols}

$\alpha$ coefficient of thermal expansion

$\Delta$ cyclic value

$\sigma$ normal stress

$\tau$ shear stress

$v$ Poisson's ratio

$\mu$ shear modulus

$\varepsilon$ normal strain

$\gamma$ shear strain

\section{Subscripts (in plain text or in italics)}

al aluminum alloy

ambient ambient temperature

applied applied value

curing curing temperature

$c 0$ composite layer with fiber along the $y$ direction

$c 90$ composite layer with fiber along the $x$ direction

ds redistributed stress

$\mathrm{f}$ fiber

induced induced value

lam laminate

ll value in $y$ direction

$\mathrm{m}$ material layer

max maximum value

P plain aluminum alloy specimen

$r$ resin

rs residual stress

rt residual strain

tip value at crack tip

tl value in $x$ direction

$x, y, z$ Cartesian coordinate system

$\otimes$ critical value

C \& IC plane stress and plane strain conditions

* value corresponding to laminate thickness 


\section{Appendix 1}

Residual strain (subscript ' $r t$ ') in material layer, $\mathrm{m}$, is found as $\{\varepsilon\}_{\mathrm{rt}, \mathrm{m}}=\left[\left\{\begin{array}{c}\alpha_{x} \\ \alpha_{y} \\ 0\end{array}\right\}_{\mathrm{m}}-\left\{\begin{array}{c}\alpha_{\mathrm{tl}} \\ \alpha_{\mathrm{ll}} \\ 0\end{array}\right\}\right] \times\left(T_{\text {cuiring }}-T_{\text {ambient }}\right)$, where $T_{\text {ambient }}=30^{\circ} \mathrm{C}$ and $T_{\text {curing }}=160^{\circ} \mathrm{C}$

Stiffness matrices of materials under plane stress conditions are

(i) Stiffness matrix of aluminum (al)

$\{\mathrm{M}\}_{\mathrm{al}}=\left[\begin{array}{ccc}\frac{E_{\mathrm{al}}}{1-v_{\mathrm{al}}^{2}} & \frac{E_{\mathrm{al}}}{1-v_{\mathrm{al}}^{2}} v_{\mathrm{al}} & 0 \\ \frac{E_{\mathrm{r}}}{1-v_{\mathrm{al}}^{2}} v_{\mathrm{al}} & \frac{E_{a l}}{1-v_{\mathrm{al}}^{2}} & 0 \\ 0 & 0 & \mu_{\mathrm{al}}\end{array}\right]=\left[\begin{array}{ccc}80.79 & 26.66 & 0 \\ 26.66 & 80.79 & 0 \\ 0 & 0 & 27.06\end{array}\right]$ $\mathrm{GPa}$

(ii) Stiffness matrix of resin (r)

$$
\{\mathrm{M}\}_{\mathrm{r}}=\left[\begin{array}{ccc}
\frac{E_{\mathrm{r}}}{1-v_{\mathrm{r}}^{2}} & \frac{E_{\mathrm{r}}}{1-v_{\mathrm{r}}^{2}} v_{\mathrm{r}} & 0 \\
\frac{E_{\mathrm{r}}}{1-v_{\mathrm{r}}^{2}} v_{\mathrm{r}} & \frac{E_{\mathrm{r}}}{1-v_{\mathrm{r}}^{2}} & 0 \\
0 & 0 & \mu_{\mathrm{r}}
\end{array}\right]=\left[\begin{array}{ccc}
3.92 & 1.29 & 0 \\
1.29 & 3.92 & 0 \\
0 & 0 & 1.25
\end{array}\right]
$$

\section{$\mathrm{GPa}$}

(iii) Stiffness matrix of fiber (f)

$$
\{\mathrm{M}\}_{\mathrm{f}}=\left[\begin{array}{ccc}
\frac{E_{\mathrm{f}}}{1-v_{\mathrm{f}}^{2}} & \frac{E_{\mathrm{f}}}{1-v_{\mathrm{f}}^{2}} v_{\mathrm{f}} & 0 \\
\frac{E_{\mathrm{f}}}{1-v_{\mathrm{f}}^{2}} v_{\mathrm{f}} & \frac{E_{\mathrm{f}}}{1-v_{\mathrm{f}}^{2}} & 0 \\
0 & 0 & \mu_{\mathrm{f}}
\end{array}\right]=\left[\begin{array}{ccc}
74.61 & 16.41 & 0 \\
16.41 & 74.61 & 0 \\
0 & 0 & 29.70
\end{array}\right]
$$

$\mathrm{GPa}$

The stiffness matrix of laminate (subscript 'lam'), $\{M\}_{\text {lam }}$ from classical theory is written as

$$
\begin{gathered}
\{\mathrm{M}\}_{\text {lam }}=\{\mathrm{M}\}_{\mathrm{al}} \times \frac{t_{\mathrm{al}} \times 3}{d}+\{\mathrm{M}\}_{\mathrm{f}} \times \frac{t_{\mathrm{f}} \times 6}{d}+\{\mathrm{M}\}_{\mathrm{r}} \times \frac{t_{\mathrm{r}} \times 12}{d} \\
=\left[\begin{array}{ccc}
61.31 & 18.13 & 0 \\
18.13 & 61.31 & 0 \\
0 & 0 & 21.72
\end{array}\right] \mathrm{GPa}
\end{gathered}
$$

(the standard thickness of material layers are taken from the 'Glare details' section)

$$
\{\mathrm{M}\}_{\text {lam }}{ }^{-1}=\left[\begin{array}{ccc}
0.0178 & -0.0052 & 0 \\
-0.0052 & 0.0178 & 0 \\
0 & 0 & 0.046
\end{array}\right]
$$

Maximum stress applied over the laminate during the fatigue cycle is

$$
\left\{\begin{array}{c}
\sigma_{x} \\
\sigma_{y} \\
\tau_{x y}
\end{array}\right\}_{\text {applied, } \max }=\left\{\begin{array}{c}
0 \\
75 \\
0
\end{array}\right\} \mathrm{MPa}
$$

The strain in laminate under maximum applied stress is $\varepsilon_{\text {lam }}=\left\{\begin{array}{c}\varepsilon_{x} \\ \varepsilon_{y} \\ \gamma_{x y}\end{array}\right\}_{\text {lam }}=\{\mathrm{M}\}_{\text {lam }}{ }^{-1} \sigma_{\text {applied }}=\left\{\begin{array}{c}-3.9 \times 10^{-4} \\ 13.35 \times 10^{-4} \\ 0\end{array}\right\}$

Maximum redistributed stress (subscript ' $\mathrm{ds}$ ') in material layer $\left\{\begin{array}{c}\sigma_{x} \\ \sigma_{y} \\ \tau_{x y}\end{array}\right\}_{\mathrm{ds}, \mathrm{m}, \max }=\{\mathrm{M}\}_{\mathrm{m}} \times \varepsilon_{\mathrm{lam}}$
The residual stress (subscript 'rs') in material layer $\left\{\begin{array}{c}\sigma_{x} \\ \sigma_{y} \\ \tau_{x y}\end{array}\right\}_{\mathrm{rs}, \mathrm{m}}=\{\mathrm{M}\}_{\mathrm{m}} \times\{\varepsilon\}_{\mathrm{rt}, \mathrm{m}}$

The maximum induced stress (subscript 'induced') in material layer $\left\{\begin{array}{c}\sigma_{x} \\ \sigma_{y} \\ \tau_{x y}\end{array}\right\}_{\text {induced, } m, \max }=\{\mathrm{M}\}_{\mathrm{m}} \times\left[\varepsilon_{\text {lam }}+\{\varepsilon\}_{\mathrm{rt}, \mathrm{m}}\right]$ The values are $\{\sigma\}_{\mathrm{ds}, \mathrm{al}, \max }=\left\{\begin{array}{c}4.083 \\ 97.45 \\ 0\end{array}\right\} \mathrm{MPa},\{\sigma\}_{\text {induced,r, } \max }=$ $\left\{\begin{array}{c}0.1932 \\ 4.729 \\ 0\end{array}\right\} \quad \mathrm{MPa}, \quad\{\sigma\}_{\text {induced }, \mathrm{f}, \max }=\left\{\begin{array}{c}-7.183 \\ 93.19 \\ 0\end{array}\right\} \mathrm{MPa}, \quad\{\sigma\}_{\mathrm{rs}, \mathrm{al}}=$ $\left\{\begin{array}{c}46.17 \\ 48.36 \\ 0\end{array}\right\} \mathrm{MPa}, \quad\{\sigma\}_{\mathrm{rs}, \mathrm{r}}=\left\{\begin{array}{c}25.59 \\ 25.73 \\ 0\end{array}\right\} \mathrm{MPa}, \quad\{\sigma\}_{\mathrm{rs}, \mathrm{f}}=$ $\left\{\begin{array}{c}-173.92 \\ -171.02 \\ 0\end{array}\right\} \operatorname{MPa}\{\sigma\}_{\text {induced,al, } \max }=\left\{\begin{array}{c}50.26 \\ 145.8 \\ 0\end{array}\right\} \mathrm{MPa},\{\sigma\}_{\text {induced, }, \mathrm{r}, \max }=$ $\left\{\begin{array}{c}25.78 \\ 30.45 \\ 0\end{array}\right\} \mathrm{MPa}$, and $\{\sigma\}_{\text {induced,f, } \max }=\left\{\begin{array}{c}-181.1 \\ -77.83 \\ 0\end{array}\right\} \mathrm{MPa}$

(note: +ve and -ve denote tensile and compressive stress, respectively; subscripts 'al', ' $r$ ', and 'f' denote aluminum, resin, and fiber, respectively).

\section{Competing interests}

The authors declare that they have no competing interests.

\section{Authors' contributions}

SB carried out theoretical and experimental work. He drafted the manuscript. SN made arrangements for material procurement, laminate fabrication and fatigue test equipment for experimental work. He framed time and activity plans. He checked the draft. All authors read and approved the final manuscript.

\section{Acknowledgements}

Authors are grateful to the Science and Engineering Research Council, Department of Science and Technology (DST), India, for funding the project. They convey their thanks to (i) Valeth Hightech Composites Pvt. Ltd., Chennai, India, for their valuable assistance in material procurement and fabrication of the laminates and (ii) Metallurgical Services, Mumbai, India, for providing the fatique test equipment. Support received from VIT University, Tamil Nadu, India and Galgotias University, U.P., India, during the course of this work is appreciated.

\section{Author details}

${ }^{1}$ School of Civil and Mechanical Engineering, Galgotias University, Greater Noida, UP 203201, India. ${ }^{2}$ School of Mechanical and Building Sciences, VIT University, Vellore, Tamil Nadu 632014, India.

\section{Received: 1 March 2014 Accepted: 13 May 2014}

Published: 18 July 2014

\section{References}

Alderliesten, RC. (2007a). Analytical prediction model for fatigue crack propagation and delamination growth in Glare. International Journal of Fatigue, 29(4), 628-646.

Alderliesten, RC. (2007b). On the available relevant approaches for fatigue crack propagation prediction in Glare. International Journal of Fatigue, 29(2), 289-304. Alderliesten, RC, \& Homan, JJ. (2006). Fatigue and damage tolerance issues of Glare in aircraft structures. International Journal of Fatigue, 28(10), 1116-1123. 
Bhat, S, \& Narayanan, S. (2014). Quantification of fibre bridging in mode I cracked Glare without delaminations. European Journal of Mechanics A/Solids, 43(1-2), 152-170.

Callister, WD, Jr. (2004). Materials science and engineering: an introduction (6th ed., pp. 737-754). India: Wiley.

Chang, PY, \& Yang, JM. (2008). Modelling of fatigue crack growth in notched fiber metal laminates. International Journal of Fatigue, 30(12), 2165-2174.

da Costa, AA, da Silva, DFNR, Travessa, DN, \& Botelho, EC. (2012). The effect of thermal cycles on the mechanical properties of fiber-metal laminates. Materials and Design, 42(12), 434-440.

Elber, W. (1976). Fatigue crack growth under spectrum loads, ASTM STP 595 (pp. 236-250). Philadelphia: American Society for Testing and Materials.

Guo, YJ, \& Wu, XR. (1998). A theoretical model for predicting fatigue crack growth rates in fiber-reinforced metal laminates. Fatigue and Fracture of Engineering Materials and Structures, 21(9), 1133-1145.

Guo, YJ, \& Wu, XR. (1999a). A phenomenological model for predicting crack growth in fiber reinforced metal laminates under constant amplitude loading. Composites Science and Technology, 59(12), 1825-1831.

Guo, YJ, \& Wu, XR. (1999b). Bridging stress distribution in center-cracked fiber reinforced metal laminates: modeling and experiment. Engineering Fracture Mechanics, 63(2), 147-163.

Homan, JJ. (2006). Fatigue initiation in fiber metal laminates. International Journal of Fatigue, 28(4), 366-374.

Irwin, GR. (1967). NRL Report 6598. Washington D.C.: Naval Research Laboratory.

Kawai, M, \& Hachinobe, A. (2002). Two stress level fatigue of unidirectional fiber-metal hybrid composite: GLARE 2. International Journal of Fatigue, 24(5), 567-580.

Kawai, M, \& Kato, K. (2006). Effects of $R$-ratio on the off-axis fatigue behavior of unidirectional hybrid GFRP/Al laminates at room temperature. International Journal of Fatigue, 28(10), 1226-1238.

Khan, SU, Alderliesten, RC, Rans, CD, \& Benedictus, R. (2010). Application of a modified Wheeler model to predict fatigue crack growth in fiber metal laminates under variable amplitude loading. Engineering Fracture Mechanics, 77(9), 1400-1416.

Kumar, P. (2009). Elements of fracture mechanics (p. 91). India: McGraw-Hill.

Lin, CT, \& Kao, PW. (1995). Effect of fiber bridging on the fatigue crack propagation in carbon fiber-reinforced aluminum laminates. Material science and Engineering A, 190(1-2), 65-73.

Lin, CT, \& Kao, PW. (1996). Delamination growth and its effect on crack propagation in carbon fiber reinforced aluminum laminates under fatigue loading. Acta Materialia, 44(3), 1181-1188.

Lin, CT, Kao, PW, \& Yang, FS. (1991). Fatigue behavior of carbon fiber-reinforced aluminum laminates. Composites, 22(2), 135-141.

Rans, CD, Alderliesten, RC, \& Benedictus, R. (2011). Predicting the influence of temperature on fatigue crack propagation in fiber metal laminates. Engineering Fracture Mechanics, 78(10), 2193-2201.

Suiker, ASJ, \& Fleck, NA. (2006). Modelling of fatigue crack tunneling and delamination in layered composites. Composites Part A: Applied Science and Manufacturing, 37(10), 1722-1733.

Shim, DJ, Alderliesten, RC, Spearing, SM, \& Burianek, DA. (2003). Fatigue crack growth prediction in GLARE hybrid laminates. Composites Science and Technology, 63(12), 1759-1767.

Takamatsu, T, Matsumura, T, Ogura, N, Shimokawa, T, \& Kakuta, Y. (1999). Fatigue crack growth properties of a GLARE3-5/4 fiber/metal laminate. Engineering Fracture Mechanics, 63(3), 253-272.

\section{doi:10.1186/s40712-014-0003-x}

Cite this article as: Bhat and Narayanan: High-cycle fatigue

investigations of notched Glare under different stress ratio's in various environments. International Journal of Mechanical and Materials

Engineering 2014 1:3.

\section{Submit your manuscript to a SpringerOpen ${ }^{\circ}$ journal and benefit from:}

- Convenient online submission

- Rigorous peer review

- Immediate publication on acceptance

- Open access: articles freely available online

- High visibility within the field

- Retaining the copyright to your article

Submit your next manuscript at $\gg$ springeropen.com 